\title{
Evaluation of the Benefits of Traffic Calming on Vehicle Speed Reduction
}

\author{
Natalia Distefano, Salvatore Leonardi* \\ Department of Civil Engineering and Architecture, University of Catania, Italy
}

Copyright $\mathrm{O} 2019$ by authors, all rights reserved. Authors agree that this article remains permanently open access under the terms of the Creative Commons Attribution License 4.0 International License

\begin{abstract}
Vehicle speed is one of the main risk factors for road traffic safety. To increase the level of road safety, especially in urban areas, measures must be implemented to reduce vehicle speed. The installation of calming measures on a road network is systematically planned way to reduce driving speeds. This paper studies the effectiveness in terms of speed reduction of three types of traffic calming measures: 1) speed table, 2) chicane, and 3) road narrowing. The speed analyses regard a series of traffic calming measures located in urban contexts of Catania Province (Italy). For each of these traffic calming measures, experimental investigations were carried out relating to the measurement of speed. The study has shown that the speed tables represent the measure of traffic calming that guarantees the greatest conditioning on speed (it is also possible to halve the average speed). Even the chicanes have a significant impact on reducing speed, as well as the speed tables (average speed is reduced by up to $50 \%$ ), while road narrowing allows maximum reductions in average speed of around 35\%. Furthermore, all three traffic calming measures have resulted in a reduction of accidents always greater than $30 \%$. In the case of speed tables, the reduction in accidents exceeds even $40 \%$. The consequences of road accidents are also mitigated thanks to the traffic calming interventions considered. The reduction of injured people is between 32\% (road narrowing) and $50 \%$ (chicane). The speed tables involve a reduction of almost $40 \%$ of injured people while fatal accidents are completely eliminated. Finally, it has been observed that the reduction in pedestrian injuries is between 33\% (road narrowing) and 50\% (speed tables). In the case of the chicane the reduction of injured pedestrians is $40 \%$. The pedestrian fatal accidents in the road section in which the speed tables were subsequently installed have been reduced to zero.
\end{abstract}

Keywords Speed Tables, Chicane, Road Narrowing, Road Accidents, Road Safety

\section{Introduction}

Vehicle speed is one of the main risk factors for road traffic safety; it affects both the accident probability and the severity [1-3].

Speeding is one of the main factors that increase the risk of a road accident; approximately $50 \%$ of drivers exceed the speed limits [4]. Speeding is the greatest challenge of road safety in many countries, often contributing to more than one third of all fatal accidents. Speed is also an aggravating factor in the severity of all accidents. In particular, speeding affects the severity of collisions and accidents which involve the most vulnerable road users i.e. pedestrians, cyclists and motorcyclists.

To increase the level of road safety, especially in urban areas, measures must be implemented to reduce vehicle speed. To keep an acceptable speed in urban areas, it requires physical speed calming measures build on the road network; it is especially the case on roads where the road design invites to driving too fast [5-7].

The installation of calming measures on a road network is systematically planned way to reduce driving speeds, but also reduces the volume of through traffic on local and residential streets. With an overall goal to improve the living environment, traffic calming is often defined, sometimes implicitly, as an integrated intervention strategy that is applied to a street network. It comprises a series of objectives, such as street safety, the promotion of active and collective transport, the reduction of noise and air pollution.

Traffic calming strategies generally aim to reduce driving speeds (often to about $30 \mathrm{~km} / \mathrm{h}$ ), and particularly those of the fastest drivers [8]. Consequently, strategies that succeed on this level can reduce the number and severity of collisions. Calming strategies, by helping create more complex environments, can induce drivers to pay more attention and, thus, reduce the number of collisions [9]. 
Traffic calming schemes generally incorporate a wide range of measures designed to complement each other in both speed reduction and environmental terms. Engineering options are more diverse and employ one or more of the following techniques: 1) narrowing 2) vertical deflection, 3) horizontal deflection, 4) restrictions.

Engineered options are designed to increase the complexity and cognitive load of driving, making the driver naturally slow down, or to create discomfort above certain speeds.

The aim of this study is to evaluate the effectiveness in terms of speed reduction of three types of traffic calming measures: 1) speed table, 2) chicane, and 3) road narrowing. The speed analyses regard a series of traffic calming measures located in urban contexts of Catania Province (Italy). The effectiveness of such measures, highlighted by results exposed in the following paragraphs, should encourage greater spread them in urban contexts.

\section{An Overview of the Literature}

There are many studies that had been carried out on traffic calming especially in Europe where the idea originated. Various researchers came up with different definitions of traffic calming, but they all converge at the general understanding that their major goal is to reduce vehicle speeds, improve road safety, and enhancing quality of life.

The most commonly used definition of traffic calming is that which defines them as: "Traffic calming is the combination of mainly physical measures that reduce the negative effects of motor vehicle use, alter driver behavior and improve conditions for non-motorized street users" [10].

Many researches show the effectiveness in reducing the speed of the traffic calming measures. Some studies use field measurements which were made on street sections with different types of traffic calming measures, in different places. These measurements were compared with other ones located on other street sections of similar characteristics but without traffic calming measures [6, 11-13]. Other studies instead use driving simulators and microsimulation-based techniques. In this regard, Reference [14] highlights how driving simulators can be used to overcome the methodological constraints that do not allow you to evaluate different ranges of interventions with comparable metrics.

However, most studies focus on assessing the effectiveness of a typology or a few types of traffic calming interventions, such as types of signage, perceptual countermeasures or physical traffic calming. Mahdy [15] focuses on vertical deflections in road alignment to study the influence of their physical and geometric characteristics on traffic performance, in terms of speed profile. Reference [16] also deals with the assessment of the effectiveness of vertical deflection devices that include speed bump, plastic speed bump, raised crosswalk, rumble strips and sinusoidal hump. Reference [7] also presents research methodology and analysis of results of vertical traffic calming measures (speed bumps, speed humps, raised crosswalks), safety islands and speed cameras influence to the road safety on Lithuanian roads. The raised island greatly reduces distractions in the behavior of the gaze and is very effective element for speed reduction $(-7.24 \mathrm{~km} / \mathrm{h})$, being very visible [17].

Reference [5] has studied the effects on speed reduction following the establishment of sinus speed humps and chicanes. Overall, chicanes and humps seem to have considerable speed-reducing effects on driving. They have almost same effect on mean speed and $85^{\text {th }}$ percentile speed. Additionally, results show a higher speed variation near and especially before chicanes compared to the humps.

Reference [18] shows that the traffic calming devices, including speed humps should be placed at appropriate distances (from 200 to $400 \mathrm{~m}$ ) to each other to achieve balancing speed and road safety benefits against capacity.

The relation between speed tables' physical characteristics and design speed of them was evaluated of experimental results in Tehran. The results of this study represent that increasing the length of speed table for only $1 \mathrm{~m}$ will averagely increase the design speed of speed tables about three $\mathrm{km} / \mathrm{h} \mathrm{[19]}$. Also, it was found that the speed reduction due to the speed tables depends mainly on the separation between traffic-calming devices, whereas the speed over the speed tables depends crucially on the entrance-ramp slope, the speed table length, and the distance from the previous traffic control device [20].

Reference [21] evaluates the effectiveness of four traffic calming measures (two types of speed humps, speed tables, and chicanes). The results show that chicane is better than the other types of traffic calming measures considered.

Several studies indicated that narrowing lanes is a measure to slow down the speed because a narrow lane may increase perceived risk. Indeed, the narrow lane width increased steering workload and reduced speeds through a speed-steering workload trade-off, whilst the hatched road centre marking enhanced peripheral visual speed perception, leading to higher speed estimations and slower speeds [22, 23]. Reference [24] measured the effectiveness of a colored slurry seal traffic calming treatment, used to "narrow" lanes of a road, in reducing driving speeds and traffic volume on residential streets.

The existing literature shows that if well designed traffic calming measures improve road safety, but it should be noted that numerous studies have shown the negative effects of these interventions on the environment (pollutants and noise). In general, it can be stated that horizontal deflections, narrowing and restrictions result in 
lower production of pollutants. Vertical deflections (e.g. bumps) often result in increases in the production of atmospheric pollutants and higher noise production [25-30].

\section{Methods}

This study is made as speed measurement campaign in specific sections of road segments where they were made traffic calming measures. Speed profiles were obtained from speed measurements.

For speed measurement, it has been used the Autovelox 104/C2, realized from the "Sodi Scientifica", based on the emission and the reception of a pair of laser beams that cross the road perpendicularly. The survey operations have been completed in 10 days.

Plots of $85^{\text {th }}$ percentile and average speeds at distances along calmed-streets indicated the speed-distance relationships that exist between starting/ending points on the street and the device and between two devices.

The starting point and the end point have been identified in those points where it is believed that the speed is not influenced by traffic calming devices. 85th percentile speed and mean speed profiles were plotted to compare the speed-reducing effect for each type of traffic calming device. The profiles provided a better understanding of how drivers react to the traffic calming devices. Furthermore, speeds at distances away from the devices and between devices were able to be studied. Influence zones generated by calming devices were also obtained from the speed profiles.

Deviations from the mean speed when traversing calming devices signify behavioural differences among drivers. A plot of standard deviations at distances along a calmed-street gave a general idea of these differences. To determine the changes in speed variations caused by calming devices the F-test for equality of variances was employed. This tested the statistical significance of differences in the standard deviation in speed between impeded segments (i.e. at the device) and unimpeded segments (i.e. at distances away from the device). It was anticipated that "more forgiving" traffic calming designs would lead to greater variations in driver speeds.

\section{Case of Study}

A case study was conducted in the Province of Catania focusing on speed table, chicane, and road narrowing in three different zones of the Province.

\subsection{Case of study ${ }^{\circ} 1$ : Speed tables}

Speed tables are wide mountable obstructions installed on the pavement surface across the travel lanes, and intended to cause vehicles to slow. Speed tables are similar to speed humps, except for the flat-topped section located between the approach and far edges; are generally wider than speed humps and are gentler on vehicles.

The investigation context is represented from the residential area that is developed around to the road called Lungo Mare Pantano Street, in Riposto city (CT). In particular, on this road are two speed tables, placed to a distance between one and the other of 40 meters, realized in bituminous conglomerate and opportunely premarked. Both speed tables have a height of $7 \mathrm{~cm}$ and have straight ramps of $10 \%$ slope (Fig. 1).

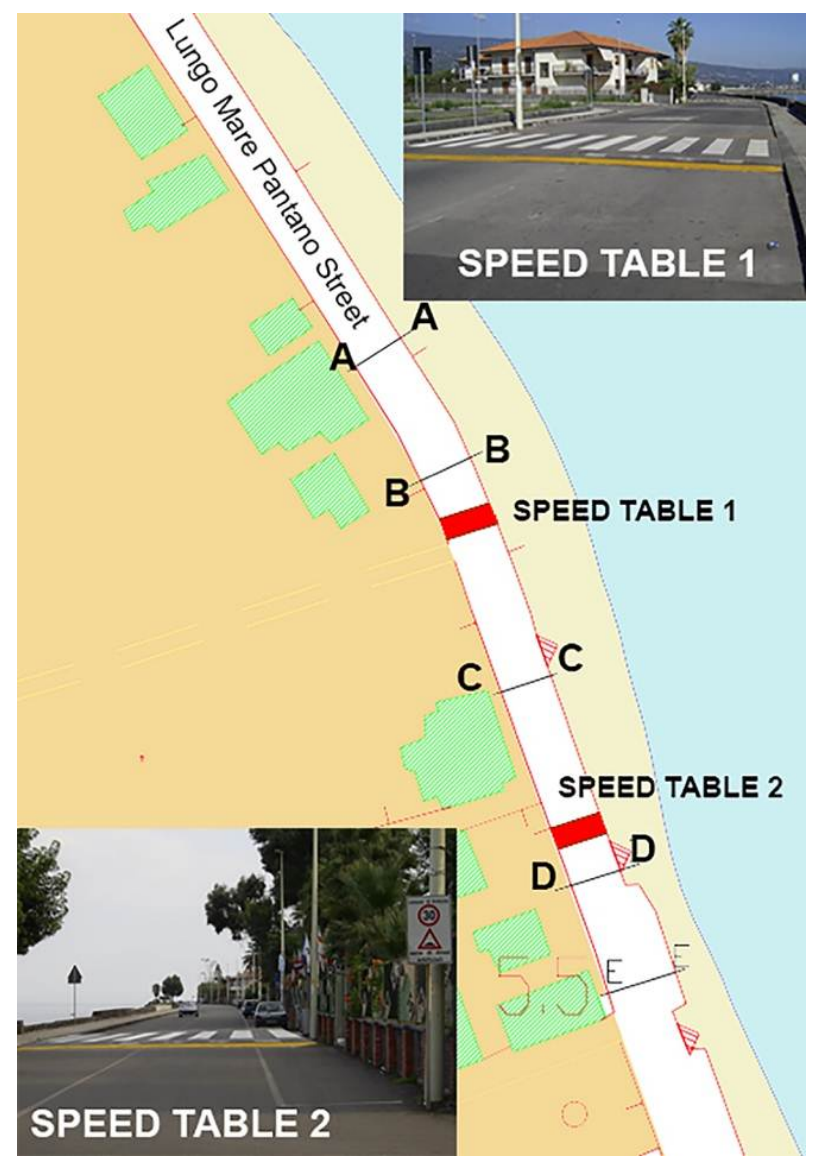

Figure 1. Speed tables in Lungo Mare Pantano street (Riposto)

In order to study adequately the variation of the cinematic characteristics of the vehicles, for effect of the speed tables presence, have been chosen the five speed measurement sections:

1) the section indicated with "A" letter, located 30 meters before the first traffic calming measure;

2) the " $B$ " section is placed $10 \mathrm{~m}$ before the first speed table;

3) the section "C" is equidistant between the 2 speed tables;

4) the "D" section is located $10 \mathrm{~m}$ after the second speed table;

5) the "E" section is placed 30 meters after the second traffic calming measure.

The distance described from the sequence of sections A, 
B, C, D and E, is downhill, with longitudinal slope of $2 \%$.

The Lungo Mare Pantano street is a road to service of an exclusively residential zone; the traffic flows, therefore, are not elevated ever, and the greater part of the vehicles is isolates. These conditions, evidently, are ideal in order to estimate the intrinsic effectiveness of any traffic calming measure. The mutual conditionings between the vehicles are practically null. Therefore, it has not been adopted the traditional criterion of selection of distinctive hourly bands for the speed measurement; to the contrary, they have been executed the continuous measures, until obtaining a statistically meaningful number of speeds values relative to the isolated vehicles.

In particular, after the experimental survey, it has been obtained the speed values of 788 vehicles for the uphill distance (156 for the " $\mathrm{A}$ " section, 150 for the "B" section, 168 for the "C" section, 153 for the " $D$ " section and 161 for the "E" section) and the speed values of 775 vehicles for the downhill distance (148 for the "A" section To, 152 for the "B" section, 156 for the " $C$ " section, 161 for the " $D$ " section and 158 for the "E" section). Subsequently the following assessments have been executed: A) the calculation of average speed $\left(\mathrm{S}_{\mathrm{a}}\right)$ on all the speed measurement sections; B) the calculation, for the same sections, of the 85 th percentile speed $\left(\mathrm{S}_{85}\right)$, that is that value of the speed that is not exceeded from $85 \%$ of the road users.

Figure 2 end figure 3 shows the speed profiles (for average speed and for $85^{\text {th }}$ percentile speed) relative to speed tables.

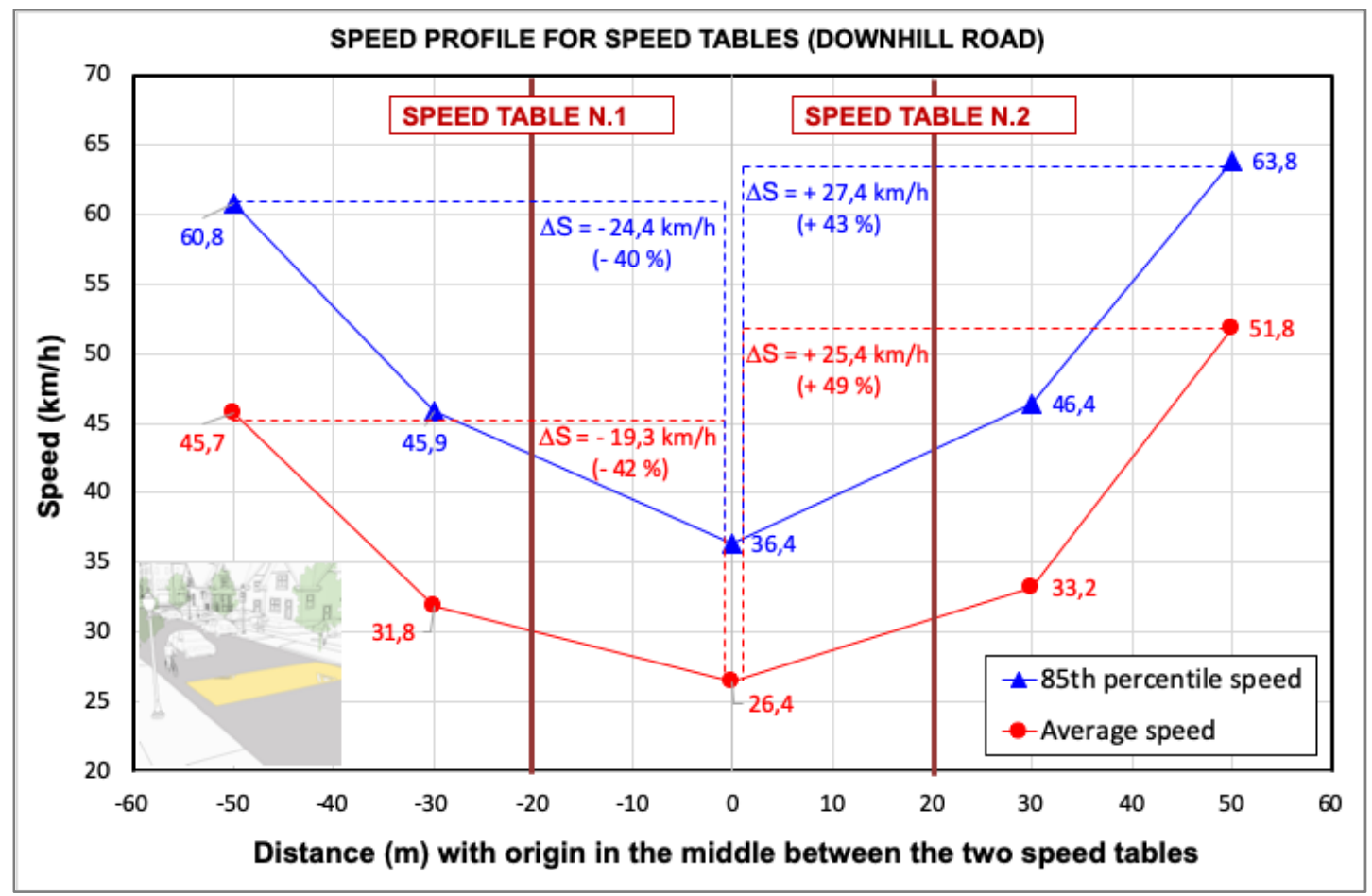

Figure 2. Speed profiles relative to speed tables (downhill road) 


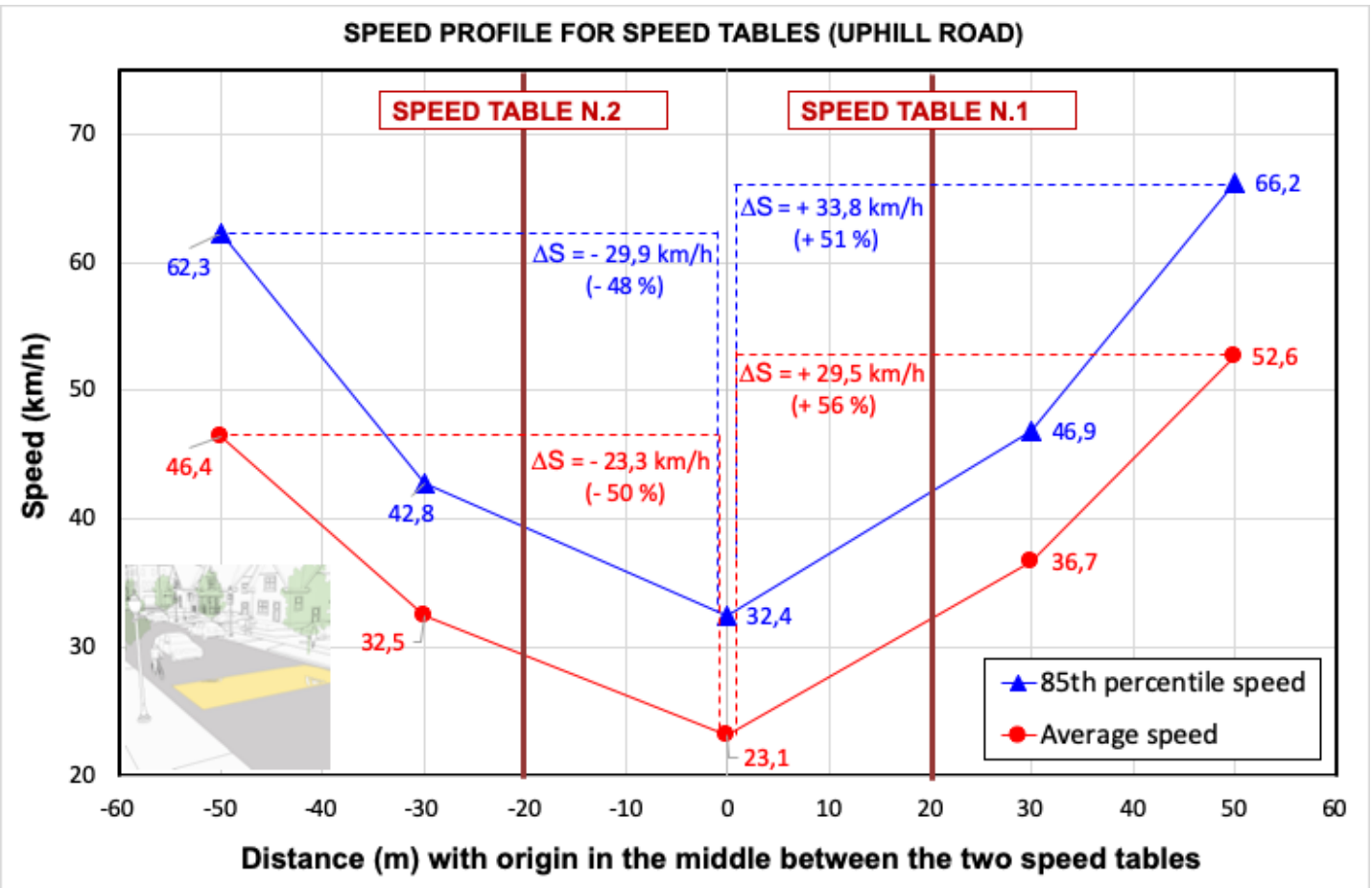

Figure 3. Speed profiles relative to speed tables (uphill road)

From the analysis of such diagrams, it is possible to note that:

- the speed profiles for Sa and for S85 show an attended result: both for the uphill road and for downhill road, has lowest speed in correspondence of road portion comprised between the speed tables;

- from the comparison between the S85 values associates to the measurement sections farther from the speed tables sequence and those relative to the intermediate sections between the two traffic calming measures, it has deduced an average reduction of $25 \mathrm{~km} / \mathrm{h}$ approximately (variation percentage of $40 \%$ ) in the case of downhill road, and an average reduction of $30 \mathrm{~km} / \mathrm{h}$ approximately (equal to $48 \%$ ) in the case of uphill road;

- from the comparison between the $\mathrm{Sa}$ values associates to the measurement sections farther from the speed tables sequence and those relative to the intermediate sections between the two traffic calming measures, it has deduced an average reduction of $19 \mathrm{~km} / \mathrm{h}$ approximately (variation percentage of $42 \%$ ) in the case of downhill road, and an average reduction of $23 \mathrm{~km} / \mathrm{h}$ approximately (equal to $50 \%$ ) in the case of uphill road.

\subsection{Case of Study ${ }^{\circ} 2$ : Chicane}

Chicane is a series of fixed objects, usually extensions of the curb, which alter a straight roadway into a zigzag or serpentine path to slow vehicles.

The chicane is located in Anastasio street (road to only direction) in the urban centre of Catania city, and is realized through two vehicle parking lines disposed alternatively on the left margin and on the right margin of the road (Fig. 4).

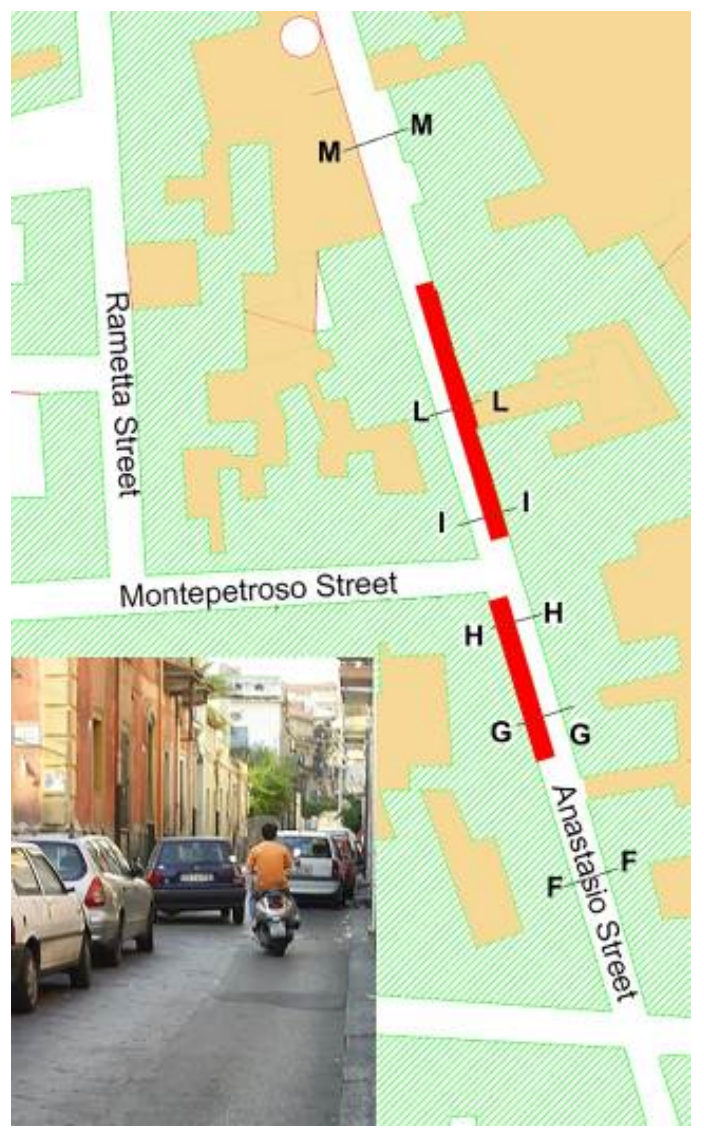

Figure 4. Chicane in Anastasio street (Catania) 
For the experimental survey, six speed measurement sections have been choices: 1) the section indicated with "F" letter, located 30 meters before the vehicle parking line on the left margin of the road; 2) the " $G$ " section, placed 5 meters after the beginning of vehicle parking line on the left margin of the road; 3 ) the " $\mathrm{H}$ " section, located 20 meters after the beginning of vehicle parking line on the left margin of the road; 4) the "I" section, placed 5 meters after the beginning of vehicle parking line on the right margin of the road; 5) the "L" section, located 20 meters after the beginning of vehicle parking line on the right margin of the road; 6) the section indicated with "M" letter, located 30 meters after the vehicle parking line on the right margin of the road. The distance described from the sequence of sections $\mathrm{F}, \mathrm{G}, \mathrm{H}, \mathrm{I}, \mathrm{L}, \mathrm{M}$ is almost in plain.

The experimental survey was performed over a two-week period. In order to estimate the real effect of the chicane like a traffic calming measure, it have been selected three-hour bands representative of three hours "of soft", that is temporal periods in which the conditionings for the road users derive mostly from the traffic calming measures presence than from the interactions with the other vehicles. The hour intervals for experimental survey, therefore, they have been: 10.00-11.00, 15.00-16.00, 16.00-17.00. After the experimental survey, finally, has been obtained the speed values of 969 vehicles ( 161 for the "F" section, 167 for the "G" section, 171 for the " $\mathrm{H}$ " section, 159 for the "I" section, 148 for the "L" section and 163 for the "M" section). Subsequently the following assessments have been executed: A) the calculation of average speed $\left(\mathrm{S}_{\mathrm{a}}\right)$ on all the speed measurement sections; B) the calculation, for the same sections, of the $85^{\text {th }}$ percentile speed $\left(\mathrm{S}_{85}\right)$.

Figure 5 shows the speed profiles (for average speed and for $85^{\text {th }}$ percentile speed) relative to chicane.

From the analysis of previous diagram, it is possible to deduce the following considerations:

- the speed profiles for Sa and for S85 evidence remarkable speed reductions during the run on the chicane;

- from the comparison between the S85 values associates to the measurement sections farther from the chicane and those relative to the intermediate sections between the two vehicle parking lines (" $\mathrm{H}$ " and "I" sections), it has deduced an average reduction of $22 \mathrm{~km} / \mathrm{h}$ approximately (variation percentage of $50 \%$ );

- from the comparison between the average speed values ( $\mathrm{Sa}$ ) associates to the measurement sections farther from the chicane and those relative to the intermediate sections between the two vehicle parking lines ("H" and "I" sections), it has deduced an average reduction of $20 \mathrm{~km} / \mathrm{h}$ approximately (variation percentage of $42 \%$ ).

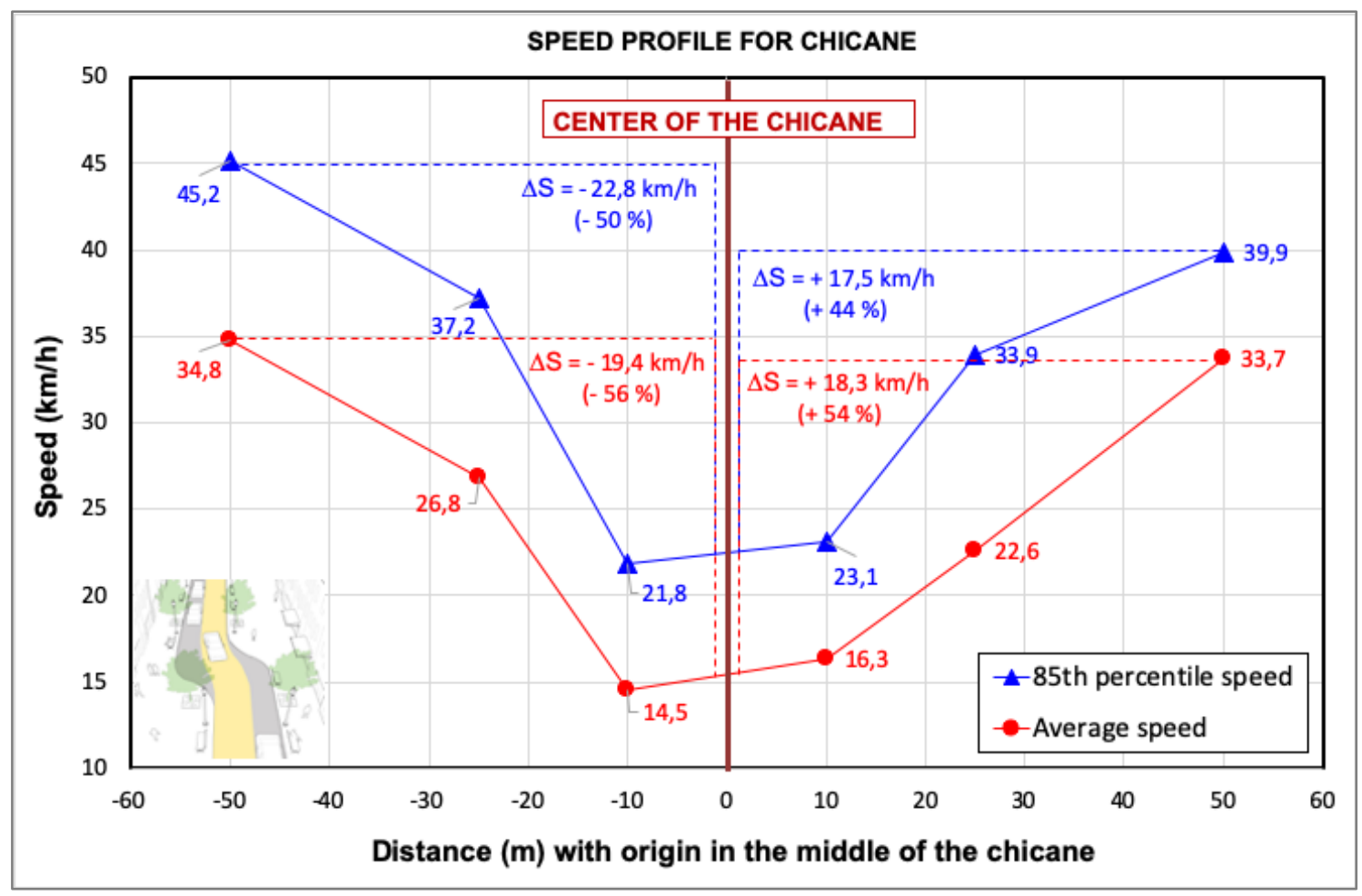

Figure 5. Speed profiles relative to chicane 


\subsection{Case of Study $n^{\circ} 3$ : Road Narrowing}

Road narrowing may be considered as a supportive measure to vertical deflections. It cannot be considered as a speed reducing device in itself, but it can act as a reminder or encouragement to drive slowly or calmly

The third measure of traffic calming analyzed is a road narrowing. Such road narrowing has not been realized "voluntarily" but is consequent to urban configuration due to the urbanization conditions and to the territory morphology (presence of substantial rocky formations). The road narrowing is located in Mandrà street (road to only direction) in the urban center of Catania city (Fig. 6). The road has initially the width of $8 \mathrm{~m}$ and subsequently it is shrunk abruptly until the minimal value of $3,10 \mathrm{~m}$ (after around 5 meters from the beginning of the narrowing, there is a subsequent narrowing of the road section up to the attainment of the total width of 2,60 m).

For the experimental survey, three speed measurement sections have been choices: 1) the section indicated with "N" letter, located 30 meters before the beginning of the abrupt narrowing; 2) the "O" section, placed 10 meters before the beginning of the narrowing; 3) the "P" section, placed 10 meters after the beginning of the narrowing. The distance described from the sequence of sections $\mathrm{N}, \mathrm{O}$ and $\mathrm{P}$ is uphill, with longitudinal slope of $1,5 \%$.

The experimental survey has been carried out for a period of one week. In order to estimate the real effect of the road narrowing like a traffic calming measure, they have been selected three-hour bands representative of three hours "of soft", that is temporal periods in which the conditionings for the road users derive mostly from the traffic calming measures presence than from the interactions with the other vehicles. The hour intervals for experimental survey, therefore, they have been: $10.00-11.00,15.00-16.00,16.00-17.00$. After the experimental survey, finally, has been obtained the speed values of 462 vehicles (148 for the "N" section, 152 for the "O" section and 162 for the "P" section). Subsequently the following assessments have been executed: A) the calculation of average speed $\left(\mathrm{S}_{\mathrm{a}}\right)$ on all the speed measurement sections; B) the calculation, for the same sections, of the $85^{\text {th }}$ percentile speed $\left(\mathrm{S}_{85}\right)$.

Figure 7 shows the speed profiles (for average speed and for $85^{\text {th }}$ percentile speed) relative to road narrowing.

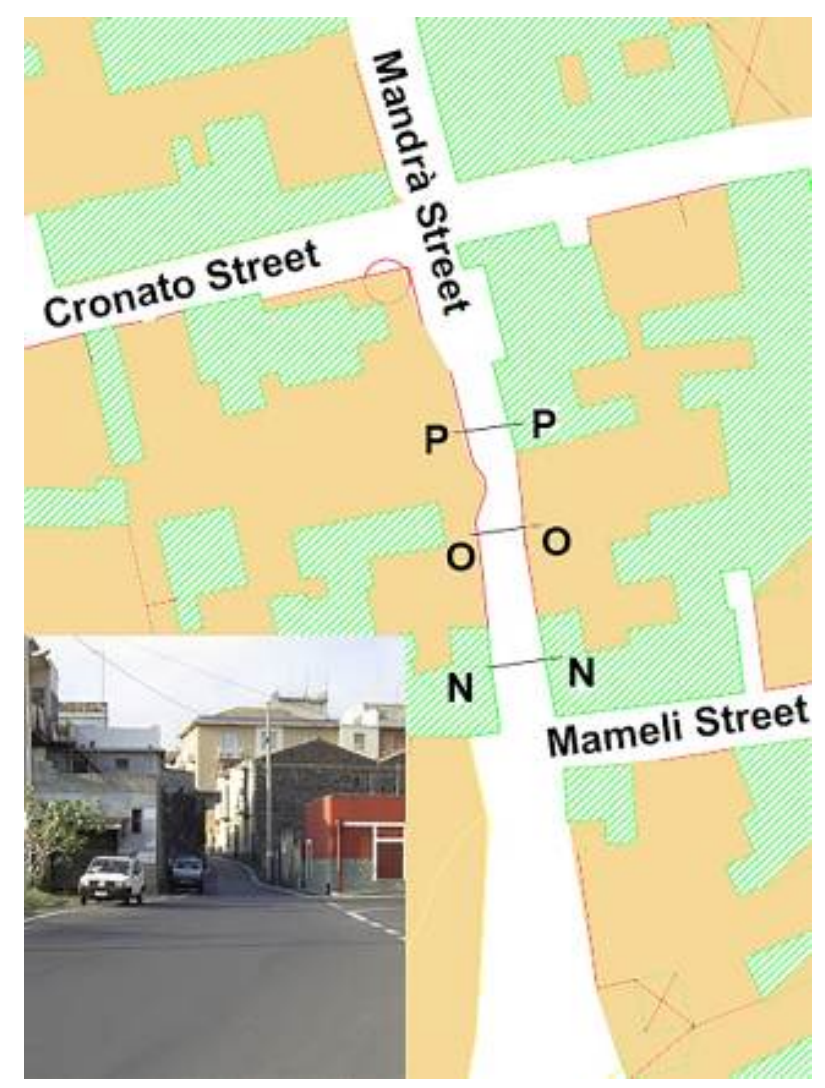

Figure 6. Road narrowing in Mandrà street (Catania) 


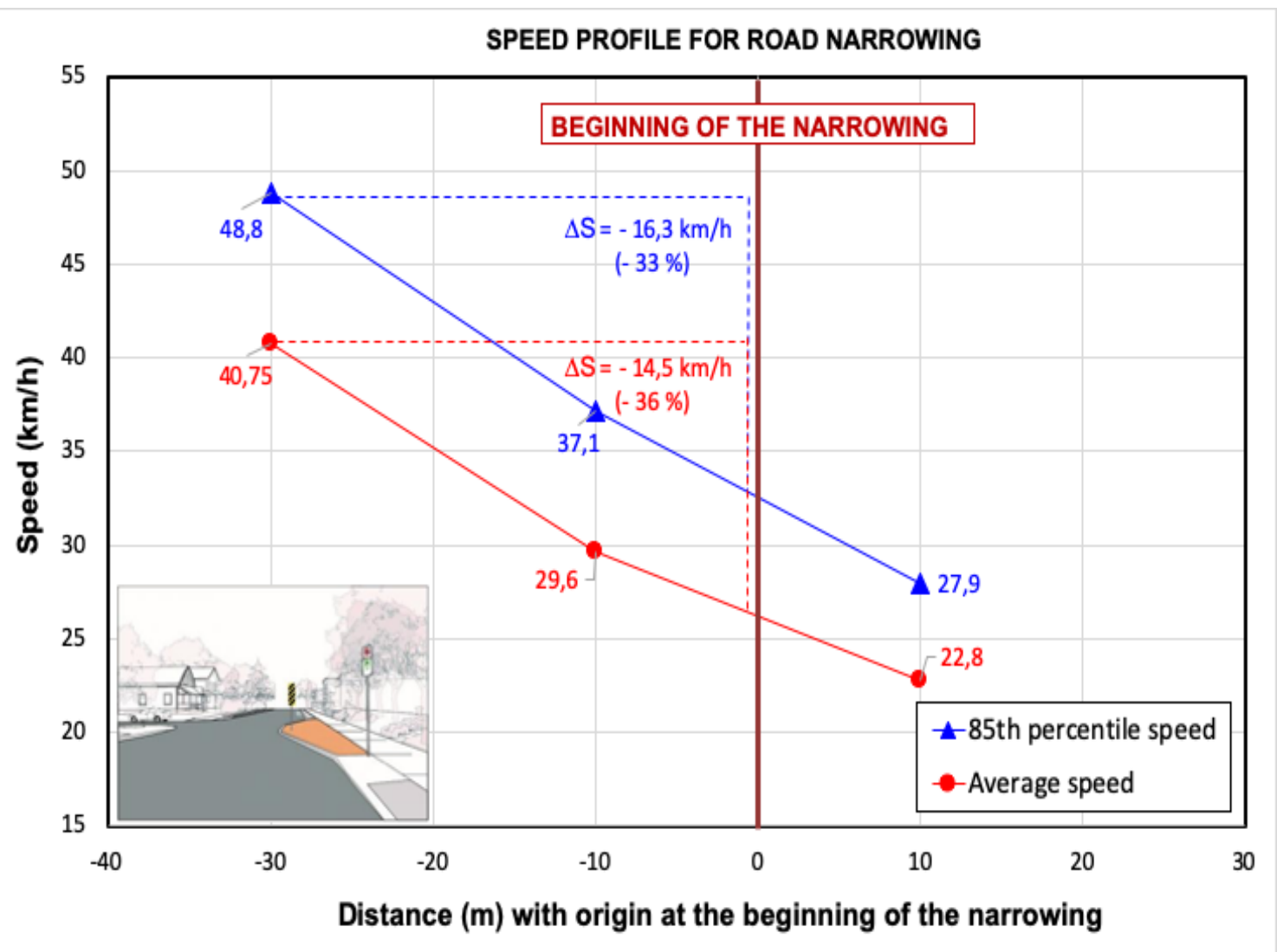

Figure 7. Speed profiles relative to road narrowing

From the analysis of previous diagram, it is possible to note that:

- the speed profiles for $\mathrm{Sa}$ and for S85 evidence remarkable speed reductions during the run on the road narrowing;

- from the comparison between the S85 values associates to the measurement section farther from the narrowing and those relative to the two sections nearer the road narrowing, it has deduced an average reduction of $16 \mathrm{~km} / \mathrm{h}$ approximately (variation percentage of $33 \%$ );

- from the comparison between the Sa values associates to the measurement section farther from the narrowing and those relative to the two sections nearer the road narrowing, it has deduced an average reduction of $15 \mathrm{~km} / \mathrm{h}$ approximately (variation percentage of $36 \%$ ).

\section{Analysis and Assessment of the Impact of Traffic Calming Measures on Road Safety}

One of the benefits directly linked to the reduction in speed induced by traffic calming measures is the improvement of the safety of the road sections in which traffic calming devices are installed.
In the case of the three traffic calming measures considered in this study, a before-after analysis was carried out referring to the accident data of the road sections where the speed tables, the chicane and the road narrowing analyzed in this paper are present.

The following situations were considered for the before-after analysis:

- road accidents (excluding those with damage to property) that occurred in Lungo Mare Pantano street in the two following time periods were considered: 5 years before the installation of the speed tables and 5 years after the installation of the speed tables;

- road accidents (excluding those with damage to property) that occurred in Anastasio street in the two following time periods were considered: 5 years before the realization of the chicane and 5 years after the realization of the chicane;

- road accidents (excluding those with damage to property) occurred in the 2013-2017 five-year period in Mandrà street (before analysis) and those that occurred in Acquedotto Greco street ("surrogate" after analysis) in the same period (2013-2017) were considered. It has already been observed that the studied narrow narrowing is an intervention not artificially realized but "naturally" due to the effect of the urbanization conditions and the territory morphology. We therefore analyzed the accidental 
story of Acquedotto Greco Street which is a parallel street to Mandrà Street characterized by the same geometric and traffic characteristics of Mandrà street but without any traffic calming device. Acquedotto Greco Street, therefore, was used as a "control site" to be compared with Mandrà Street regarding the accidents that occurred in the same five-year period.

Table 1 shows the results of the before-after analysis relating to the road sites where the traffic calming measures considered in this research are present.

Analysis of fatal and injury accident data on the road sections, where the speed tables were placed, showed that the number of fatal and injury accidents decreased by about $44 \%$, the number of people killed - by $100 \%$, the number of people injured - by about $38 \%$. On the section where the chicane has been realized the number of fatal and injury accidents decreased by about $36 \%$, the number of people killed - by $100 \%$, and the number of people injured - by $50 \%$. On the road section where the road narrowing was placed the number of fatal and injury accidents decreased by about $33 \%$, the number of people injured - by about $32 \%$.

Table 1 clearly shows that speed tables are particularly effective in reducing accidents involving pedestrians. Indeed, in the five-year period following the installation of the speed tables, there were no longer any pedestrians dead in road accidents (in the previous five years there had been 2 dead pedestrians) and, moreover, the number of pedestrians injured in accidents decreased by $50 \%$.

In the case of the chicane, there was a reduction in the number of injured pedestrians in road accidents by around
$40 \%$ and in the case of road narrowing by $33 \%$.

The reduction of speeds in road sections characterized by the presence of traffic calming measures examined in this study is certainly the cause of the reduction in the number of dead and injured pedestrians [31]. This has also been demonstrated by several studies that correlate the reduction of speed due to the installation of traffic calming devices with the mitigation of the gravity of the consequences on pedestrians of accidents. Indeed, impact speed is the most significant crash factor affecting the injury risks in vehicle-to-pedestrian crashes. Although the strong correlation between the impact speed and pedestrian injury probability has been well established based on pedestrian crash data, the absolute pedestrian injury probability as a function of impact speed is still controversial [32]. Specifically, Reference [32] found that studies conducted before 2000 were all based on direct analyses of data with oversampling of severe and fatal injuries, resulting in overestimation of pedestrian fatality probability. On the other hand, more recent studies based on less biased data provided substantially lower probability estimates than those previously reported. Figure 8 shows the fatality probability functions from different studies [33]. Regardless of the absolute values of fatality probabilities, there is a consensus that pedestrian fatality probability increases monotonically with vehicle impact speed.

With reference to the three traffic calming measures presented in this paper, table 2 shows the pedestrian death probabilities deducted by means of the correlations shown in Figure 8, considering the average values of the 85th percentile speed reported in figures 2, 3, 5 and 7 .

Table 1. Change in the number of fatal and injury accidents after installation of traffic calming measures

\begin{tabular}{|c|c|c|c|c|}
\hline & & $\begin{array}{l}\text { Number of accidents } \\
(5 \text { years })\end{array}$ & $\begin{array}{l}\text { Number of people killed } \\
(5 \text { years })\end{array}$ & $\begin{array}{l}\text { Number of people injured } \\
(5 \text { years })\end{array}$ \\
\hline \multirow{4}{*}{ Speed tables } & Before & $\begin{array}{l}18 \text { (9 accidents with pedestrians } \\
\text { involved) }\end{array}$ & 2 (2 pedestrian) & 29 (8 pedestrian) \\
\hline & After & $\begin{array}{l}10 \text { (4 accidents with pedestrians } \\
\text { involved) }\end{array}$ & 0 & 18 (4 pedestrian) \\
\hline & Reduction (absolute) & 8 & 2 & 11 \\
\hline & Reduction (\%) & $44 \%$ & $100 \%$ & $38 \%$ \\
\hline \multirow{4}{*}{ Chicane } & Before & $\begin{array}{l}14 \text { (5 accidents with pedestrians } \\
\text { involved) }\end{array}$ & 1 & 30 ( 5 pedestrian) \\
\hline & After & $\begin{array}{l}9 \text { (3 accidents with pedestrians } \\
\text { involved) }\end{array}$ & 0 & 15 ( 3 pedestrian $)$ \\
\hline & Reduction (absolute) & 5 & 1 & 15 \\
\hline & Reduction (\%) & $36 \%$ & $100 \%$ & $50 \%$ \\
\hline \multirow{4}{*}{$\begin{array}{l}\text { Road } \\
\text { narrowing }\end{array}$} & Before & $\begin{array}{l}15 \text { (5 accidents with pedestrians } \\
\text { involved) }\end{array}$ & 0 & 28 (6 pedestrian) \\
\hline & $\begin{array}{l}\text { After ("surrogate" } \\
\text { analysis) }\end{array}$ & $\begin{array}{l}10 \text { ( } 3 \text { accidents with pedestrians } \\
\text { involved) }\end{array}$ & 0 & 19 (4 pedestrian) \\
\hline & Reduction (absolute) & 5 & 0 & 9 \\
\hline & Reduction (\%) & $33 \%$ & - & $32 \%$ \\
\hline
\end{tabular}




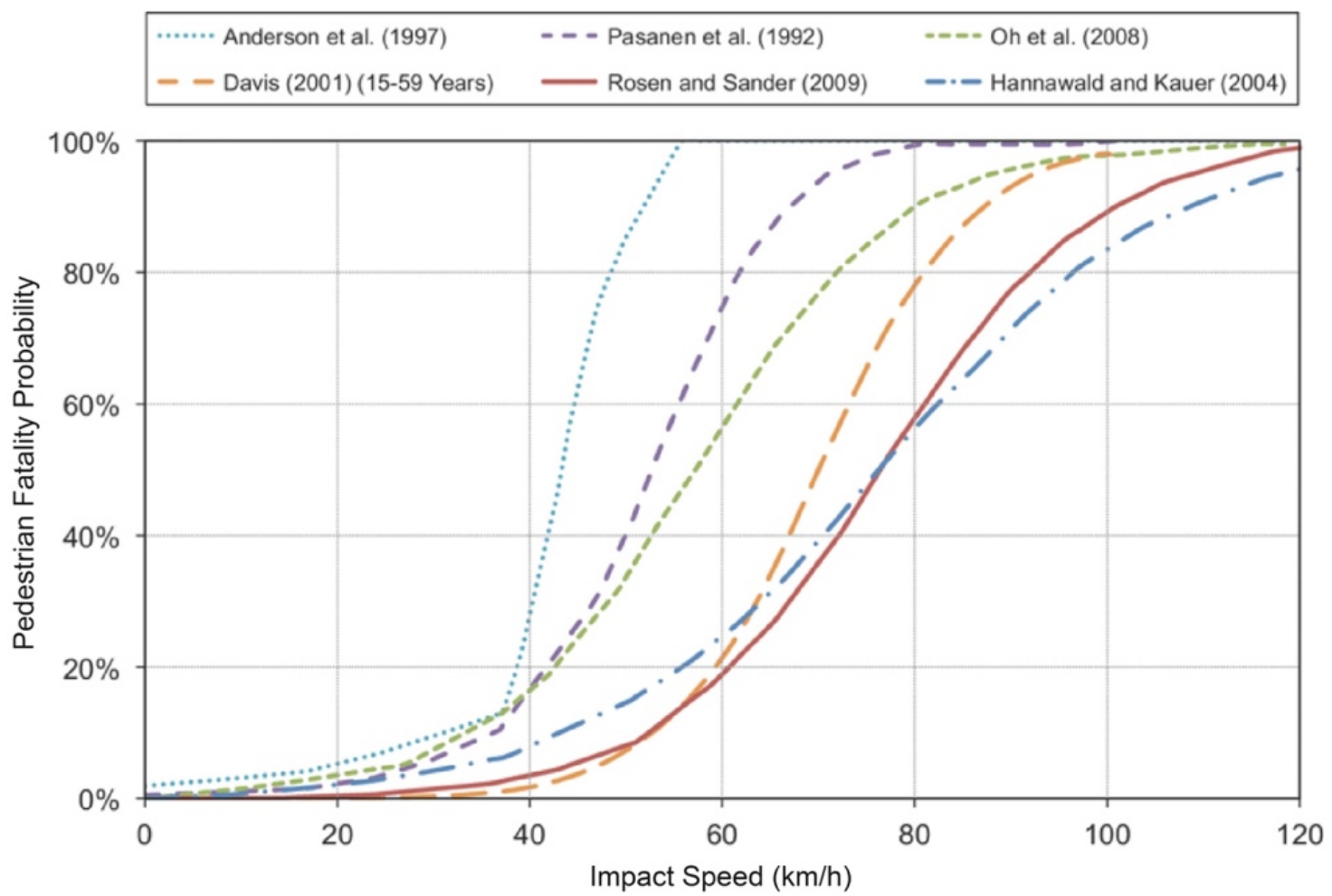

Figure 8. Pedestrian fatality probability as a function of impact speed in vehicle to pedestrian crashes

Table 2. Change in pedestrian fatality probability before and after installation of traffic calming measures

\begin{tabular}{|c|c|c|c|c|}
\hline $\begin{array}{c}\text { Traffic calming } \\
\text { measure }\end{array}$ & $\begin{array}{c}\text { Speed } \\
\text { (before) }\end{array}$ & $\begin{array}{l}\text { Speed } \\
\text { (after) }\end{array}$ & $\begin{array}{c}\text { Pedestrian fatality probability } \\
\text { (before) }\end{array}$ & $\begin{array}{c}\text { Pedestrian fatality probability } \\
\text { (after) }\end{array}$ \\
\hline \multirow{6}{*}{ Speed table } & \multirow{6}{*}{$60 \mathrm{~km} / \mathrm{h}$} & \multirow{6}{*}{$40 \mathrm{~km} / \mathrm{h}$} & $100 \%{ }^{(l)}$ & $25 \%^{(l)}$ \\
\hline & & & $75 \%^{(2)}$ & $15 \%^{(2)}$ \\
\hline & & & $55 \%^{(3)}$ & $15 \%^{(3)}$ \\
\hline & & & $20 \%^{(4)}$ & $4 \%{ }^{(4)}$ \\
\hline & & & $18 \%^{(5)}$ & $2 \%^{(5)}$ \\
\hline & & & $25 \%{ }^{(6)}$ & $8 \%{ }^{(6)}$ \\
\hline \multirow{6}{*}{ Chicane } & \multirow{6}{*}{$45 \mathrm{~km} / \mathrm{h}$} & \multirow{6}{*}{$25 \mathrm{~km} / \mathrm{h}$} & $75 \%^{(l)}$ & $8 \%{ }^{(1)}$ \\
\hline & & & $30 \%^{(2)}$ & $6 \%{ }^{(2)}$ \\
\hline & & & $57 \%^{(3)}$ & $6 \%^{(3)}$ \\
\hline & & & $6 \%{ }^{(4)}$ & $1 \%{ }^{(4)}$ \\
\hline & & & $7 \%{ }^{(5)}$ & $2 \%{ }^{(5)}$ \\
\hline & & & $12 \%^{(6)}$ & $4 \%{ }^{(6)}$ \\
\hline \multirow{6}{*}{ Road narrowing } & \multirow{6}{*}{$50 \mathrm{~km} / \mathrm{h}$} & \multirow{6}{*}{$30 \mathrm{~km} / \mathrm{h}$} & $83 \%^{(l)}$ & $10 \%^{(l)}$ \\
\hline & & & $37 \%^{(2)}$ & $6 \%^{(2)}$ \\
\hline & & & $35 \%^{(3)}$ & $7 \%{ }^{(3)}$ \\
\hline & & & $5 \%{ }^{(4)}$ & $0,8 \%^{(4)}$ \\
\hline & & & $5 \%{ }^{(5)}$ & $0,9 \%^{(5)}$ \\
\hline & & & $13 \%{ }^{(6)}$ & $4 \%{ }^{(6)}$ \\
\hline
\end{tabular}

(1) Correlation by Anderson et al. (1997)

(2) Correlation by Pasanen et al. (1992)

(3) Correlation by Oh et al. (2008)

(4) Correlation by Davis (2001)

(5) Correlation by Rosen and Sander (2009)

(6) Correlation by Hannawald and Kauer (2004) 
Table 3. Comparison between expected number of pedestrian fatal accidents and actual number

\begin{tabular}{|c|c|c|c|c|c|c|}
\hline $\begin{array}{c}\text { Traffic } \\
\text { calming } \\
\text { measure }\end{array}$ & $\begin{array}{c}\text { Pedestrian } \\
\text { accidents } \\
\text { (before) }\end{array}$ & $\begin{array}{c}\text { Pedestrian } \\
\text { accidents } \\
\text { (after) }\end{array}$ & $\begin{array}{c}\text { Number of } \\
\text { pedestrians killed, } \\
\text { evaluated with } \\
\text { correlations in the } \\
\text { literature (before) }\end{array}$ & $\begin{array}{l}\text { Actual number } \\
\text { of pedestrians } \\
\text { killed (before) }\end{array}$ & $\begin{array}{c}\text { Number of } \\
\text { pedestrians killed, } \\
\text { evaluated with } \\
\text { correlations in the } \\
\text { literature (after) }\end{array}$ & $\begin{array}{l}\text { Actual number } \\
\text { of pedestrians } \\
\text { killed (after) }\end{array}$ \\
\hline \multirow{6}{*}{ Speed table } & \multirow{6}{*}{8} & \multirow{6}{*}{4} & $8,00^{(l)}$ & \multirow{6}{*}{2} & $1,00^{(I)}$ & \multirow{6}{*}{0} \\
\hline & & & $6,00^{(2)}$ & & $0,6^{(2)}$ & \\
\hline & & & $4,40^{(3)}$ & & $0,6^{(3)}$ & \\
\hline & & & $1,60^{(4)}$ & & $0,16^{(4)}$ & \\
\hline & & & $1,44^{(5)}$ & & $0,08^{(5)}$ & \\
\hline & & & $2,00^{(6)}$ & & $0,32^{(6)}$ & \\
\hline \multirow{6}{*}{ Chicane } & \multirow{6}{*}{5} & \multirow{6}{*}{3} & $3,75^{(1)}$ & \multirow{6}{*}{0} & $0,24^{(l)}$ & \multirow{6}{*}{0} \\
\hline & & & $1,50^{(2)}$ & & $0,18^{(2)}$ & \\
\hline & & & $2,85^{(3)}$ & & $0,18^{(3)}$ & \\
\hline & & & $0,30^{(4)}$ & & $0,03^{(4)}$ & \\
\hline & & & $0,35^{(5)}$ & & $0,06^{(5)}$ & \\
\hline & & & $0,60^{(6)}$ & & $0,12^{(6)}$ & \\
\hline \multirow{6}{*}{$\begin{array}{c}\text { Road } \\
\text { narrowing }\end{array}$} & \multirow{6}{*}{6} & \multirow{6}{*}{4} & $4,98^{(1)}$ & \multirow{6}{*}{0} & $0,40^{(1)}$ & \multirow{6}{*}{0} \\
\hline & & & $2,22^{(2)}$ & & $0,24^{(2)}$ & \\
\hline & & & $2,10^{(3)}$ & & $0,28^{(3)}$ & \\
\hline & & & $0,30^{(4)}$ & & $0,03^{(4)}$ & \\
\hline & & & $0,30^{(5)}$ & & $0,04^{(5)}$ & \\
\hline & & & $0,78^{(6)}$ & & $0,16^{(6)}$ & \\
\hline
\end{tabular}

(1) Correlation by Anderson et al. (1997)

(2) Correlation by Pasanen et al. (1992)

(3) Correlation by Oh et al. (2008)

(4) Correlation by Davis (2001)

(5) Correlation by Rosen and Sander (2009)

(6) Correlation by Hannawald and Kauer (2004)

Furthermore, since the probability of pedestrian mortality can be obtained from the number of pedestrian fatalities divided by the total number of pedestrian accidents, it is possible to compare the expected number of pedestrian fatal accidents with the actual number. The result of this evaluation is shown in table 3 .

From the analysis of table 3 it can be noted that:

1) the actual number of accidents (equal to 2) before the installation of the speed tables and after the installation of them (equal to 0 ) is strongly correlated with that expected by the formulas of Davis (2001), Rosen and Sander (2009), Hannawald and Kauer (2004). Totally different and clearly overestimated are the predictions provided by the older correlation formulas, i.e. by Anderson et al. (1997), by Pasanen et al. (1992) and by Oh et al. (2008);

2) no fatal accidents actually occurred in the road sections where the chicane and road narrowing are present, both before and after their realization. This prediction is, also in this case, compatible with the predictions provided by the correlations Davis (2001), Rosen and Sander (2009) and Hannawald and Kauer (2004).
Ultimately, the before-after analysis related to the accidents occurring in the road sections where the investigated traffic calming measures are located reveals how these measures, inducing a significant speed reduction, contribute to improving the level of safety offered to users.

With specific reference to accidents involving pedestrians, it was possible to compare the actual effectiveness of traffic calming measures analyzed with the effectiveness deduced through the correlations present in the literature. A significant correspondence was found between the real data and those deduced from the correlations elaborated after the year 2000. This constitutes an interesting confirmation of the greater reliability of the more recent correlations, as indeed already highlighted by other researchers.

\section{Discussion and Conclusions}

Life on the streets is strictly related to the characteristics of built spaces. Duarte [34] describes the streets as a meeting place for people. While they allow movement 
from a place to another, they themselves are a place where one can go and stay for a while. The movement that brings life to the streets constitutes both people who use it for passage, as well as people who reside and/or work near them.

According to Pharoah [35], vibrant streets need people on foot to exist, as their presence is a valuable attribute. However, this pedestrian presence has always been underestimated, since planning priorities were always towards controlling vehicular traffic. Even today, even when pedestrians and cyclists are considered in traffic policies, the problem remains because only their flows are analyzed. The fact of the matter is that street vitality is produced by pedestrian activities, consisting of people passing by as well as those staying in the streets; their presence is as important as their flow [36].

Some authors demonstrated that the introduction of traffic calming measures is associated with the improvement in health and behaviour of people, who manifest a better disposition to walk and to allow children to play outside and walk to school $[37,38]$.

Areas of traffic coexistence, environmental areas and areas wherein the maximum speed would be $30 \mathrm{~km} / \mathrm{h}$ configure a multiform profile of instruments to change the pattern of urban mobility. All of these have shared roots and a common virtue: they are the practical results of a reflection that questions the universal validity of the automobile in the city, and recovers the social and environmental values of the street.

Reference [39] has identified the criteria to ensure safe spaces that are comfortable and pleasant for residents, divided those into three groups that provide comfort, pleasure and protection.
Comfort emanates from opportunities to participate in diverse activities and to enjoy the surroundings, and this depends on how the city is designed to facilitate participation in basic human activities under ideal conditions. The pedestrians should be able to move freely, stay and sit wherever they feel well and natural. A good urban space must have multiple uses, including activities for passive and active recreation. Pleasure from the creation of pleasant spaces depends fundamentally on the use of special qualities, attractions and opportunities found in urban spaces.

Protection expresses our need to be safe from accidents, insecurity and discomfort: a) people should be instilled with a sense of security against crime so that there is a legitimate feeling of safety when walking around the city; b) people need to be allayed of their fear of accidents so that they can walk without the threat of being run over by vehicles.

Road safety is therefore one of the fundamental requirements that must be guaranteed by cities.

Indeed, the results of traffic reduction measures must be evaluated not only from the point of view of improving street life, but also from the optics of engineering and safety.

In this paper the effectiveness of three specific traffic calming measures was evaluated, both from the point of view of the reduction of the speed induced in the drivers, and from that of the reduction of road accidents, with special reference to those accidents involving pedestrians.

The Figure 9 shows speed reduction (85th percentile and average speeds) due to traffic calming devices starting from points in the road segment where the speed is not affected by these devices.

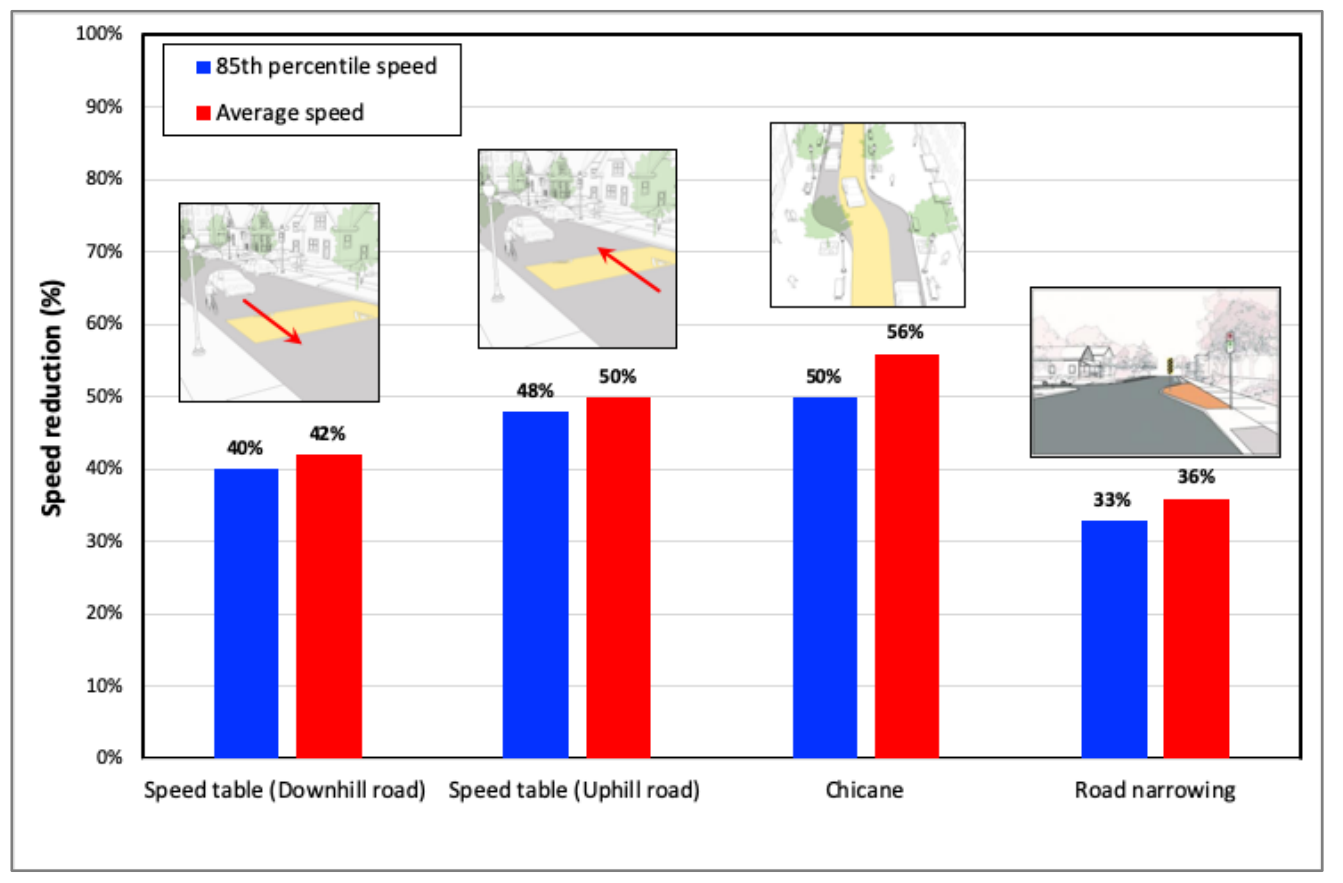

Figure 9. Effectiveness traffic calming devices 
It is possible to note that all three traffic calming devices analyzed have a high effectiveness in terms of speed reduction. Indeed, speed reductions up to half of the initial value (and beyond) can be obtained both with the chicane and with the speed tables. The speed reduction imposed by road narrowing is minor (around 35\%).

Particularly interesting is the result deriving from the study of the chicane. The transverse translation of the road axis has led to a significant reduction in the starting speed due to the effect of the two consecutive steering operations imposed on the user in a reduced space; this has helped to increase the level of attention and reduce the speed of maneuvering.

While the other intervention of the same type (horizontal offset), represented by the road narrowing, generates mainly a psychological constraint and users soon acquire the awareness that the narrowing, even if abrupt, is not a physical obstacle to the transit of vehicles and, therefore, it can be tackled with a moderate mental effort (this produces the reduction of more than a third of the initial speed).

Finally, the effectiveness of speed tables is compatible with the physical and mental commitment resulting from having to face a vertical offset on the pavement. With this study it was possible to estimate the speed variations induced by the contemporary contribution of speed tables and the longitudinal slope of the path. The longitudinal slope of the road segment, even if not high ( $2 \%$ ), however, contributed to generating a difference of about 10 percentage points between the uphill configuration (speed reduction of about $50 \%$ ) and the downhill configuration (speed reduction around $40 \%$ ).

It is important to highlight how the results of this research are consistent with those found in literature, with reference to traffic calming devices having characteristics similar to those studied. In particular, based on American and Canadian experiences, the results of which are contained in the Canadian guide to neighborhood traffic calming [40], the presence of speed tables results in reduced operating speeds of up to about $75-80 \%$ of the initial value. In any case, on roads characterized by operating speeds between $50 \mathrm{~km} / \mathrm{h}$ and $60 \mathrm{~km} / \mathrm{h}$, there was no decrease in speed below $42 \mathrm{~km} / \mathrm{h}$.

Reference [41] found that chicanes provided the best performance among the selected traffic calming devices considered in terms of speed reduction and acceleration noise but not in terms of environmental and public health impact. These are correlations compatible with the results of our research. Finally, Harvey [42] shows, consistent with the results of our study, that road narrowing results in a strong reduction in speed, in the case of configurations that cause the road to be reduced to a single lane.

Furthermore, in the present study the safety advantages were evaluated through the before-after analysis of the incidents that occurred in the road sections where the traffic calming measures considered were present. All three traffic calming measures have resulted in a reduction of accidents always greater than $30 \%$. In the case of speed tables, the reduction in accidents exceeds even $40 \%$. The consequences of road accidents are also mitigated thanks to the traffic calming interventions considered: a) the reduction of injured people is between 32\% (road narrowing) and 50\% (chicane) and in the case of speed tables injured people will reduce by almost $40 \%$; b) fatal accidents are completely eliminated.

Of particular note are the safety advantages for pedestrians. It has been observed that the reduction in pedestrian injuries is between 33\% (road narrowing) and $50 \%$ (speed tables). In the case of the chicane the reduction of injured pedestrians is $40 \%$. The pedestrian fatal accidents in the road section in which the speed tables were subsequently installed have been reduced to zero.

The authors believe it is important to note that the reductions in speeds and in road accidents caused by the traffic mitigation measures analyzed in this study, since they are confirmed by much of the technical literature, can be taken as a reference for those road contexts, similar to those studied.

Several cities have implemented traffic calming measures to reduce vehicle speed and to increase road safety. If the traffic calming measures were distributed warily and systematically on all the urban road net, it could be obtained, with a little investment, a result of great importance both in terms of safety and, more in general terms, in terms of ethicality.

The future development of this research will be to understand if the presence of the interventions analyzed in the present study can be considered effective also to reduce the amount of vehicular traffic present in the streets where such interventions are carried out. Through a specific questionnaire it will be evaluated if the conditionings due to the traffic calming measures present in the road can also influence the choice of the path to take to reach a certain destination starting from a certain origin. The investigation techniques based on the surveys already tested by the authors, also via the web [43], represent a very effective tool to evaluate how different interventions aimed at improving road safety are really perceived by the users. The use of these techniques then becomes indispensable in cases in which it is not possible to evaluate through experimental investigations how a certain intervention affects the behavior of road users.

\section{Acknowledgements}

This work has been partially financed by the University of Catania within the project "Piano della Ricerca Dipartimentale 2016-2018" of the Department of Civil Engineering and Architecture. 


\section{REFERENCES}

[1] A.A.M. Aljanahi, A.H. Rhodes, A.V. Metcalfe. Speed, speed limits and road traffic accidents under free flow conditions. Accident Analysis and Prevention 31, 161-168, 1999.

[2] V. Gitelmana, E. Doveh, S. Bekhor. The Relationship between Free-Flow Travel Speeds, Infrastructure Characteristics and Accidents, on Single-Carriageway Roads. Transportation Research Procedia 25, 2026-2043, 2017.

[3] E. De Pauwa, S. Daniels, L. Franckx, I. Mayeres. Safety effects of dynamic speed limits on motorways. Accident Analysis \& Prevention, 114, 83-89, 2018.

[4] G. Yannis, G. Louca, S. Vardaki, G. Kanellaidis. Why do drivers exceed speed limits? European Transport Research Review, 5(3), 165-177, 2013.

[5] N. Agerholm, D. Knudsen, K. Variyeswaran. Speed-calming measures and their effect on driving speed Test of a new technique measuring speeds based on GNSS data. Transportation Research Part F: Traffic Psychology and Behaviour, 46(B), 263-270, 2017.

[6] H. Gonzalo-Orden, M. Rojo, H. P $\sqrt{ }$ Crez-Acebo, A. Linares. Traffic Calming Measures and their Effect on the Variation of Speed. Transportation Research Procedia, 18, 349-356, 2016.

[7] L. Jateikiene, T. Andriejauskas, I. Lingyte, V. Jasiuniene. Impact Assessment of Speed Calming Measures on Road Safety. Transportation Research Procedia, 14, 4228-4236, 2016.

[8] Transportation Demand Management Encyclopedia. Traffic Calming: Roadway Design to Reduce Traffic Speeds and Volumes. Federal Highway Administration, Washington DC. 2010

[9] R. Ewing. Impacts of traffic calming. Transportation Quarterly 55(1), 33-45, 2001.

[10] M. Lockwood. ITE Traffic Calming Definition. Ite Journal 67(7), 22-24, 1997

[11] L. Chen, C. Chen, R. Ewing, C.E. McKnight, R. Srinivasan, M. Roe. Safety countermeasures and crash reduction in New York City - Experience and lessons learned. Accident Analysis and Prevention, 50, 312-322, 2013.

[12] R. Ewing, L. Chen, C. Chen, C. Quasi-experimental study of traffic calming measures in New York City. Transportation Research Record, 2364, 29-35, 2013.

[13] F. Rahman, A. Kojima, H. Kubota. Investigation on North American traffic calming device selection practices. IATSS Research, 33(2), 105-119, 2009.

[14] S. Jamson, F. Lai, H. Jamson. Driving simulators for robust comparisons: A case study evaluating road safety engineering treatments. Accident Analysis and Prevention, 42, 961-971, 2010.

[15] H. Mahdy. Speed calming using vertical deflections in road alignment. CICTP 2012: Multimodal Transportation Systems - Convenient, Safe, Cost-Effective, Efficient Proceedings of the 12th COTA International Conference of
Transportation Professionals, 2085-2094 2012.

[16] S. Rokade, R. Kumar, V. Rokade, S. Dubey, V. Vijayawargiya. Assessment of effectiveness of vertical deflection type traffic calming measures and development of speed prediction models in urban perspective. International Journal of Civil Engineering and Technology, 8(5), 1135-1146, 2017.

[17] C. Lantieri, R. Lamperti, A. Simone, M. Costa, V. Vignali, C. Sangiorgi, G. Dondi. Gateway design assessment in the transition from high to low speed areas. Transportation Research Part F: Traffic Psychology and Behaviour, 34, 41-53, 2015.

[18] A. Abdi, H. Bigdeli Rad, E. Azimi. Simulation and analysis of traffic flow for traffic calming. Proceedings of the Institution of Civil Engineers - Municipal Engineer, 170(1), 16-28, 2017.

[19] A. Falamarzi, R.A.O.K. Rahmat. Using appropriate speed tables regarding to the speed limit of streets. Research Journal of Applied Sciences, Engineering and Technology, 7, 2741-2746, 2014.

[20] A. Moreno, A. Garc $\downarrow \neq a$, M. Romero. Speed table evaluation and speed modeling for low-volume crosstown roads. Transportation Research Record, 2203, 85-93, 2011.

[21] G. Lee, S. Joo, C. Oh, K. Choi. An evaluation framework for traffic calming measures in residential areas. Transportation Research Part D: Transport and Environment, 25, 68-76, 2013.

[22] S.T. Godley, T.J. Triggs, B.N. Fildes. Perceptual lane width, wide perceptual road centre marking and driving speeds. Ergonomics, 47, 237-256, 2004.

[23] J. Deller. The influence of road design speed, posted speed limits and lane widths on speed selection-a literature synthesis. Australasian Transport Research Forum 2013 Proceedings, Brisbane, Australia. 2 - 4 October 2013.

[24] A. Hadayeghi, B. Malone, S. McIntyre. Impact of road lane narrowing traffic calming treatments on speed and volume. TAC/ATC 2006 - 2006 Annual Conference and Exhibition of the Transportation Association of Canada: Transportation without Boundaries. 2006.

[25] J. Casanova, N. Fonseca. Environmental assessment of low speed policies for motor vehicle mobility in city centres. Global Nest Journal, 14(2), 192-201, 2012.

[26] B. Daham, G.E. Andrews, H. Li, M. Partridge, M.C. Bell, J. Tate. Quantifying the effects of traffic calming on emissions using on-road measurements. 2005 SAE World Congress, Detroit, MI, United States, 2005.

[27] N. Distefano, S. Leonardi. Experimental investigation of the effect of speed bumps in sequence on noise emission level from motor vehicles. Noise Control Engineering Journal, 63(6), 582-597, 2015.

[28] G. Ghafghazi, M. Hatzopoulou. Simulating the air quality impacts of traffic calming schemes in a dense urban neighborhood. Transportation Research Part D: Transport and Environment, 35, 11-22, 2015.

[29] C.A. Kaffure, A. Garcia, A. Tsui Moreno, C. Llorca. Experimental study of noise produced by passenger cars on traffic calming devices. Carreteras, 4(189), 8-17, 2013. 
[30] G. Watts. Noise and vibration nuisance from traffic calming measures. Turkish Acoustical Society - 36th International Congress and Exhibition on Noise Control Engineering, INTER-NOISE 2007 ISTANBUL, 2, 830-839, 2007.

[31] S. Canale, N. Distefano, S. Leonardi. Comparative analysis of pedestrian accidents risk at unsignalized intersections. The Baltic Journal of Road and Bridge Engineering, vol.10, n. $4,2015$.

[32] E. Rosén, H. Stigson, U. Sander. Literature review of pedestrian fatality risk as a function of car impact speed. Accident Analysis and Prevention, 43(1), 25-33 (2011).

[33] J. Hu, K. Klinich. Toward designing pedestrian-friendly vehicles. International Journal of Vehicle Safety, 8(1), 2012.

[34] C. F. Duarte. Forma e Movimento. Viana \& Mosley, Rio de Janeiro, Brazil, 2006.

[35] T. Pharoah. Streets with people, or roads with cars? Walk21 Conference, Toronto, Canada, 2007.

[36] H. M. Barbosa, O. B. Neto. Impacts of traffic calming interventions on urban vitality. Urban Design and Planning. Vol. 169 (DP2), 78-90, 2016.

[37] D. S. Morrison, H. Thomson, M. Petticrew. Evaluation of the health effects of a neighbourhood traffic calming scheme. Journal of Epidemiology and Community Health, $58,837-840,2004$

[38] N. Distefano, S. Leonardi, G. Pulvirenti. Home-school Travel: Analysis of Factors Affecting Italian Parents' Mode Choice. Civil Engineering and Architecture, 7 (3), 75-87, 2019.

[39] J. Gehl, L. Gemzøe, S. Kirknaes. New City Life. The Danish Architectural Press, Copenhagen, Denmark, 2006.

[40] Transportation Association of Canada. Canadian guide to neighbourhood traffic calming. Canadian Institution of Transportation Engineers, 1998.

[41] G. Lee, S. Joo, C. Oh, K. Choi. An evaluation framework for traffic calming measures in residential areas. Transportation Research Part D 25, 68-76, 2013.

[42] T. Harvey. A Review of Current Traffic Calming Techniques. Institute for Transport Studies, University of Leeds, Leeds, UK, 1992.

[43] N. Distefano, S. Leonardi, G. Pulvirenti. Factors with the greatest influence on drivers' judgment of roundabouts safety. An analysis based on web survey in Italy. IATSS Research, 42 (4), 265-273, 2018. 